\title{
Surgical treatment of ventricular septal defect
}

\author{
VIK ING OLOV B J ÖR K \\ From the Department of Thoracic Surgery, University Hospital, Uppsala, Sweden
}

Since the first report of direct vision closure of ventricular septal defects in eight patients by Lillehei, Cohen, Warden, Ziegler, and Varco (1955), and further pioneering work by Lillehei and his group and by Kirklin, Harshbarger, Donald, and Edwards (1957), the surgical treatment of ventricular septal defect has been a well established and accepted procedure. In 1957 Lillehei and his associates reported a study of 154 patients who had ventricular septal defects and who were operated on with 45 deaths, giving an overall mortality of $29 \cdot 3 \%$. Cleland and his associates in 1958 reported 15 patients operated on with ventricular septal defects with only one death. Cooley (1959) reported a series of 130 patients operated on for ventricular septal defects. Of those under 1 year of age at operation there was a mortality of $41 \%$ in a group of 29 patients. In 10 patients between the ages of 1 and 2 years there was a mortality of $30 \%$. In the group between 2 and 5 years the mortality dropped down to $6 \%$. The conclusion Cooley drew from this was that if possible the operation should be postponed until the child is 18 months old.

The aim of this paper is to give an account of continued experience with the transatrial approach for closure of a ventricular septal defect (Björk, 1964), a method first recommended by Kay and others (1960).

\section{INDICATIONS}

Regarding the indications for closure of ventricular septal defects, I consider that patients with a significant shunt and normal pressures should have their ventricular septal defects closed at a relatively early stage. Such a defect may not be much more than $10 \mathrm{~mm}$. in diameter and may not give serious symptoms until late in life. For example, a woman who was 50 years old when first seen had had a murmur since the age of 9 years. The heart size was $650 \mathrm{ml} . / \mathrm{m}^{2}{ }^{2}$ body surface, and heart catheterization showed a shunt of $50 \%$ on the ventricular level with a systolic pulmonary artery pressure of $35 \mathrm{~mm}$. $\mathrm{Hg}$. On account of her age and normal pressures in the pulmonary artery the patient was not operated on but was observed. After one year there was a slight increase in the heart size to $700 \mathrm{ml} . / \mathrm{m}^{2}$ body surface, and two years after the first investigation the heart had increased in size to $800 \mathrm{ml} . / \mathrm{m}^{2}$ body surface; operation was then advised. During this procedure the right ventricular pressure was found to have increased to $75 / 10 \mathrm{~mm}$. $\mathrm{Hg}$, and a ventricular septal defect of 10 to $15 \mathrm{~mm}$. in diameter was closed with a patch. Immediately after the operation there was only a slight decrease in the right ventricular pressure from 75 to $60 \mathrm{~mm}$. $\mathrm{Hg}$ and the patient needed post-operative respirator treatment for 10 days.

Three years after surgery the patient is in good condition, and the right ventricular pressure has decreased to $28 \mathrm{~mm}$. $\mathrm{Hg}$; the size of the heart has also decreased to $690 \mathrm{ml} . / \mathrm{m}^{2}$. However, the working capacity was only 300 kilopondmeters $/ \mathrm{min}$., suggesting irreversible damage by the extra workload on the heart for so many years. At a workload of $250 \mathrm{kilopondmeters} / \mathrm{min}$. the right ventricular pressure had risen from $28 / 3 \mathrm{~mm}$. $\mathrm{Hg}$ to $55 / 5 \mathrm{~mm}$. $\mathrm{Hg}$. I think this case illustrates what can happen when a patient has a medium-sized ventricular septal defect, a normal pulmonary arterial pressure, a significant shunt but no other symptoms. After many years there may be a sudden deterioration with increased pulmonary arterial pressure leading to a dilatation of the heart and severe symptoms. Therefore I believe patients without symptoms but with a significant shunt of $50 \%$ should be accepted for surgery at an early stage, and even in childhood. The decision to accept patients with symptoms, with an enlarged heart, and with significant shunts is easier to make, also patients with a very high pulmonary arterial pressure should be operated upon as long as there is a dominating left to right shunt on the ventricular level. Only the presence of severe pulmonary vascular resistance leading to reversal of the intracardiac shunt constitutes a contraindication to surgery.

In this study the right ventricular pressure was above $70 \mathrm{~mm} . \mathrm{Hg}$ in 14 patients, between 40 and $69 \mathrm{~mm}$. $\mathrm{Hg}$ in 10 patients, and below $40 \mathrm{~mm}$. $\mathrm{Hg}$ in five patients. 


\section{TECHNIQUE}

In the first instance the direct suture technique described by Kirklin et al. (1957) was used with two recurrences of the shunt in 14 cases of ventricular septal defect and with two recurrences in 11 cases of Fallot's tetralogy. Then a second layer of stitches was inserted with a patch of teflon or pericardium added on top of the suture line. The results were not significantly improved as there were two recurrences in eight cases. Of the six cases with recurrence after direct suture, four had a ventricular septal defect of $15 \mathrm{~mm}$. and two of $20 \mathrm{~mm}$. diameter. None of the 12 cases with a defect of $10 \mathrm{~mm}$. diameter or less had a recurrence after closure by direct suture (Table I).

T A B LE I

CORRELATION BETWEEN SIZE OF VENTRICULAR SEPTAL DEFECT AND RECURRENCE AFTER CLOSURE BY DIRECT SUTURE

\begin{tabular}{c|c|c|c}
\hline \multirow{2}{*}{$\begin{array}{c}\text { Size of Defect } \\
(\mathrm{mm} .)\end{array}$} & $\begin{array}{c}\text { No. of } \\
\text { Cases }\end{array}$ & \multicolumn{2}{|c}{ Recurrence } \\
\cline { 3 - 4 } & No. & $\%$ \\
\hline 10 & 12 & 0 & \\
15 & 4 & 4 & 24 \\
20 & 2 & 50 \\
\hline Total & 33 & 6 & 18 \\
\hline
\end{tabular}

In a 6-year-old boy with a ventricular septal defect of $15 \mathrm{~mm}$. diameter a direct suture was carried out, but before closure of the sternum a murmur was audible. Blood samples showed an oxygen tension in the right atrium of $51 \mathrm{~mm}$. $\mathrm{Hg}$ and in the pulmonary artery of $71 \mathrm{~mm}$. $\mathrm{Hg}$. Because closure was incomplete the patient was again connected to the extracorporeal circulation for insertion of a prosthesis. The total perfusion time was 105 minutes and there was an uneventful recovery, no shunt, and a right ventricular pressure of $30 \mathrm{~mm}$. $\mathrm{Hg}$ ( $55 \mathrm{mg}$. $\mathrm{Hg}$ before operation) at recatheterization one and a half years after operation. After this experience a patch of teflon or dacron was always fixed with isolated mattress sutures without tension and buffered with teflon pearls in every ventricular septal defect of $10 \mathrm{~mm}$. or more diameter. A patch was used in 19 ventricular septal defects with one recurrence, and in 28 cases of Fallot's tetralogy with nne recurrence. For an analysis of the recurrences the cases of ventricular septal defect and Fallot's tetralogy are grouped together in $\mathbf{8 0}$ operations (Table

T A B L E I I

RESIDUAL SHUNT AFTER OPERATION FOR VENTRICULAR SEPTAL DEFECT AND FALLOT'S TETRALOGY

\begin{tabular}{|c|c|c|c|}
\hline \multirow{2}{*}{ Technique } & \multirow{2}{*}{$\begin{array}{l}\text { No. of } \\
\text { Cases }\end{array}$} & \multicolumn{2}{|c|}{ Recurrence } \\
\hline & & No. & $\%$ \\
\hline $\begin{array}{l}\text { Direct suture } \\
\text { Direct suture + second layer } \\
\text { Patch }\end{array}$ & $\begin{array}{r}25 \\
8 \\
47\end{array}$ & $\begin{array}{l}4\} \\
2\} \\
2\end{array}$ & $\begin{array}{r}18 \\
4\end{array}$ \\
\hline Total & 80 & 8 & 10 \\
\hline
\end{tabular}

II). Of those, 44 were recatheterized or investigated at necropsy, and the remainder were judged on clinical grounds alone. The recurrence rate was then found to be $18 \%(6 / 33)$ in patients with direct closure, with or without a second layer of reinforcement with a teflon or pericardial patch. The recurrence was found posteriorly where the direct suture included the base of the septal tricuspid leaflet. At re-operation in four patients the thickened edges around the remaining hole could be used for a direct suture. As a comparison, an incidence of $4 \%(2 / 44)$ was found when a patch was used.

In patients with large ventricular septal defects without any ridge between the pulmonary artery and the aorta it was necessary to insert the buffered mattress sutures from the aorta behind the base of the aortic cusp in two patients by the right atrial approach and in one patient from the pulmonary artery behind a pulmonary valve by the transventricular approach. These sutures from the aorta or pulmonary artery were placed over strips of dacron to prevent their cutting through (Fig. 1). In one such patient, a 37-year-old

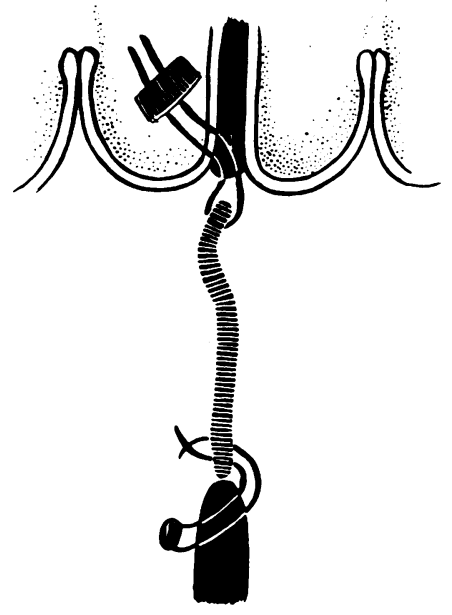

FIG. 1. The upper mattress sutures are placed through the root of the aorta to the upper portion of the prosthesis. These sutures from the aorta or pulmonary artery must be placed over strips of dacron to prevent their cutting through.

man with a huge heart of $940 \mathrm{ml} . / \mathrm{m}^{2}$ body surface and a right ventricular pressure of $85 \mathrm{~mm}$. $\mathrm{Hg}$, a 25 to $35 \mathrm{~mm}$. defect was closed by 21 mattress sutures, four of which were placed through the root of the aorta to the upper portion of the prosthesis. The pressure immediately dropped to $25 \mathrm{~mm}$. $\mathrm{Hg}$, but the patient needed a respirator for 30 days after the operation. Two years later heart catheterization showed no shunt, a right ventricular pressure of $30 \mathrm{~mm}$. $\mathrm{Hg}$. and a heart size of $480 \mathrm{ml} . / \mathrm{m}^{2}{ }^{2}$ body surface and no symptoms. 
In this study there was an immediate decrease of right ventricular pressure at the end of operation with an average of $30 \mathrm{~mm}$. $\mathrm{Hg}$ (range $4-70 \mathrm{~mm}$. $\mathrm{Hg}$ ). Then there was a further decrease of right ventricular pressure during the first year after operation with an average of $20 \mathrm{~mm}$. $\mathrm{Hg}$ (range $5-67 \mathrm{~mm}$. $\mathrm{Hg}$ ).

\section{HEART BLOCK}

The direct suture technique had an incidence of $15 \%$ (five cases) total block (see Table III). Two patients with a ventricular septal defect complicated by a total block died two days and one year after operation respectively. Two patients with Fallot's tetralogy died after a block complicating a direct suture closure, and the third patient with situs inversus totalis is still alive three years after operation; but with heart block.

T A B L E I I I

INCIDENCE OF BLOCK IN CORRELATION WITH THE TECHNIQUE

\begin{tabular}{|c|c|c|c|c|c|}
\hline & \multicolumn{2}{|c|}{$\begin{array}{l}\text { Ventricular } \\
\text { Septal Defect }\end{array}$} & \multicolumn{2}{|c|}{$\begin{array}{r}\text { Fallot's } \\
\text { Tetralogy }\end{array}$} & \multirow{2}{*}{ Total } \\
\hline & $\begin{array}{l}\text { No. of } \\
\text { Cases }\end{array}$ & Block & $\begin{array}{l}\text { No. of } \\
\text { Cases }\end{array}$ & Block & \\
\hline $\begin{array}{l}\text { Direct suture } \\
\text { Patch }\end{array}$ & $\begin{array}{l}18 \\
19\end{array}$ & $\begin{array}{l}2 \\
0\end{array}$ & $\begin{array}{l}15 \\
28\end{array}$ & $\begin{array}{l}3 \\
2\end{array}$ & $\begin{array}{l}5(15 \%) \\
2(4 \%)\end{array}$ \\
\hline Total & 37 & $2(5 \%)$ & 43 & $5(12 \%)$ & 7 \\
\hline
\end{tabular}

None of the 19 isolated ventricular septal defects with a patch had a block, but one was present in two of the 28 patients with Fallot's tetralogy. One of these died four days after operation in block; the other is still alive one year after operation. As the resting pulse rate of 50 could increase during a work-

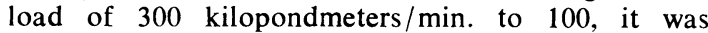
thought that pacemaker treatment was not indicated. One 4-year-old girl with Fallot's tetralogy treated with a patch in the ventricular septum and an outflow prosthesis carried out on the narrow pulmonary artery to its bifurcation had a total block treated by pacemaker for seven months when sinus rhythm returned. Three years after surgery she was much improved. There was no shunt, but there was right bundle branch block, a right ventricular pressure of $98 \mathrm{~mm} . \mathrm{Hg}$, and narrow pulmonary arterial branches.

\section{CONCLUSION}

For the closure of ventricular septal defects a patch of dacron is preferred in all cases where the aperture is of $10 \mathrm{~mm}$. or more diameter. Isolated mattress sutures buffered with teflon pearls over the myocardium are placed in the posterior half of the circumference, leaving the last 3 to $5 \mathrm{~mm}$. free from the edges of the defect. The sutures are placed from the right atrial side through the base of the septal tricuspid leaflet about $2 \mathrm{~mm}$. from its insertion (Fig. 2). Then a continuous suture of 3-0 silk can complete the fixation of the patch (Fig. 3).

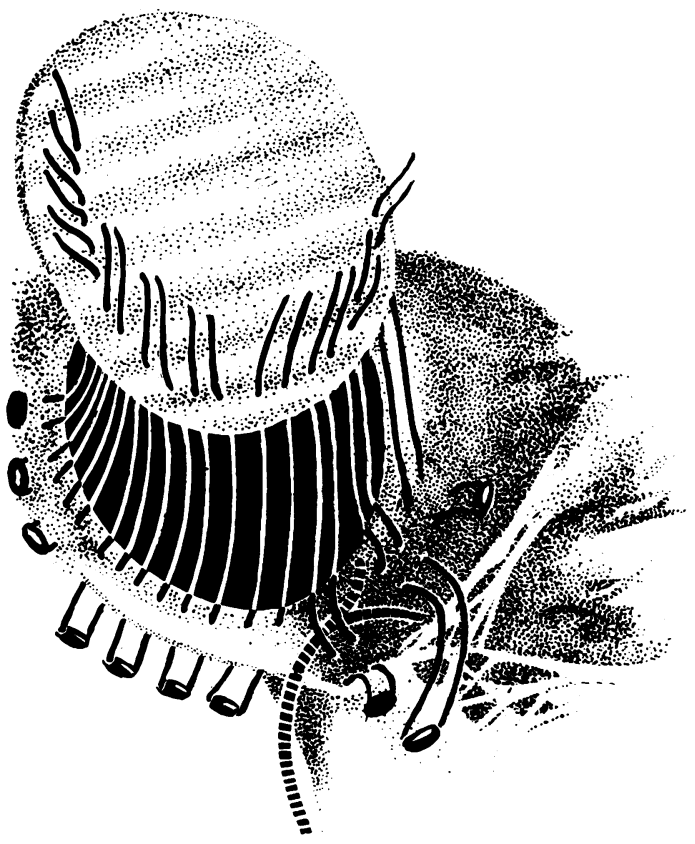

FIG. 2. Isolated mattress sutures buffered with teflon pearls are placed in the posterior half of the circumference 3-4 $\mathrm{mm}$. from the edges of the muscular part of the defect and through the septal tricuspid leaflet about $2 \mathrm{~mm}$. from its insertion. In this way the bundle of His can be avoided.

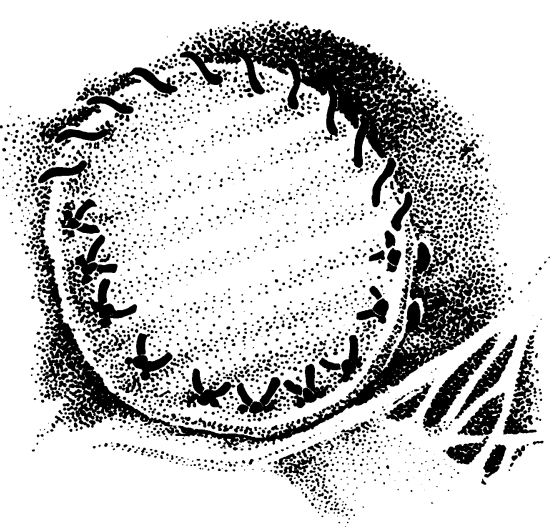

FIG. 3. A continuous suture of 3-0 silk can complete the fixation of the dacron patch. 


\section{THE TRANSATRIAL APPROACH}

The transatrial approach was used in 19 consecutive cases with ventricular septal defects with two deaths and in another six with Fallot's tetralogy with one death. The patients who died were a $1 \frac{1}{2}$-year-old boy with pulmonary hypertension of $80 \mathrm{~mm}$. $\mathrm{Hg}$ and fibroelastosis, a 31-year-old man with pulmonary hypertension of $90 \mathrm{~mm} . \mathrm{Hg}$ and a huge heart of 1,020 $\mathrm{ml} . / \mathrm{m}^{2}$ body surface, and a 15-year-old cyanotic, Blalock-operated girl with Fallot's tetralogy. The conclusions drawn from this experience are as follows :

For the transatrial approach it is necessary to work on a flaccid heart. Therefore the aorta is clamped and the heart is packed in crushed ice. Aortic occlusion should not be continued for more than 30 minutes, and preferably five minutes of coronary perfusion is performed every 20 minutes. The defect is first palpated through the right auricular appendage. Cardiopulmonary bypass is started, the aorta is crossclamped, and the heart is packed in crushed ice. The right atrium is then opened from the inferior vena cava to the incision in the auricular appendix $1 \mathrm{~cm}$. from the atrioventricular groove. In eight of the 19 cases of ventricular septal defect it was necessary to make an incision $3 \mathrm{~mm}$. from, and parallel to, the base of the septal tricuspid leaflet to obtain a good exposure of the defect. As a result of the jet effect of the shunt through the defect the septal tricuspid leaflet was always thickened and easy to close with an isolated or running suture without any evidence of tricuspid insufficiency.

In two patients an additional correction for tricuspid insufficiency had to be carried out. A 6-year-old girl with a left-to-right shunt of $70 \%$ on the ventricular level and a pulmonary hypertension with a right ventricular pressure of $125 \mathrm{~mm}$. $\mathbf{H g}$ was found to have a 20 to $15 \mathrm{~mm}$. diameter ventricular septal defect. An anomaly was found in that chordae tendineae from the septal tricuspid leaflet inserted on a papillary muscle in the left ventricle through the septal defect (Fig. 4). When the prosthesis was sutured in the defect one third of the septal tricuspid leaflet came down into the left ventricle through the posterior corner of the defect (Fig. 5). It was then necessary to suture the septal tricuspid leaflet remaining in the right ventricle to the edge of the anterior tricuspid leaflet to avoid a tricuspid insufficiency (Fig. 6). In retrospect it would have been easier to make a slit in the prosthesis and place the abnormal papillary muscle in its centre. The patient made an uneventful recovery without palpable tricuspid insufficiency and with a drop in right ventricular pressure from 125 to $60 \mathrm{~mm}$. $\mathrm{Hg}$ at the same systemic pressure of $140 \mathrm{~mm}$. $\mathrm{Hg}$. One year later the patient was in excellent condition. The right ventricular pressure was $40 / 6 \mathrm{~mm}$. $\mathrm{Hg}$, the right atrial pressure $6 \mathrm{~mm}$. and there were no signs of shunt, of tricuspid stenosis or of insufficiency.

The second case of tricuspid insufficiency was a 15-year-old boy who had a tetralogy of Fallot; it was

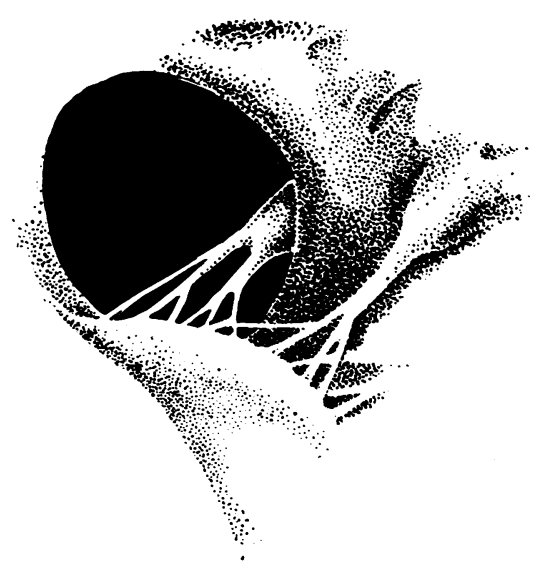

FIG. 4. Chordae tendineae from the septal tricuspid leaflet inserted on a papillary muscle in the left ventricle through the septal defect.

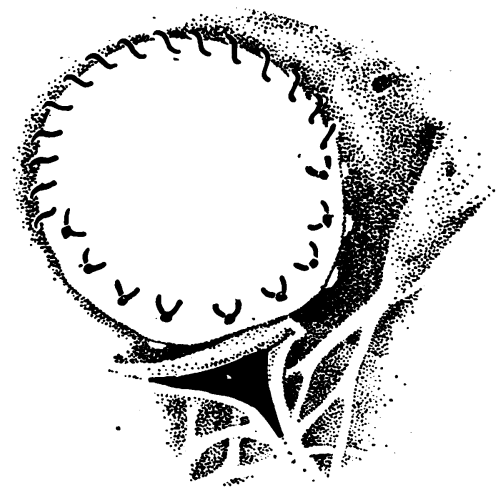

FIG. 5. One-third of the septal tricuspid leaflet came down into the left ventricle through the posterior corner of the defect when the prosthesis was sutured in place.

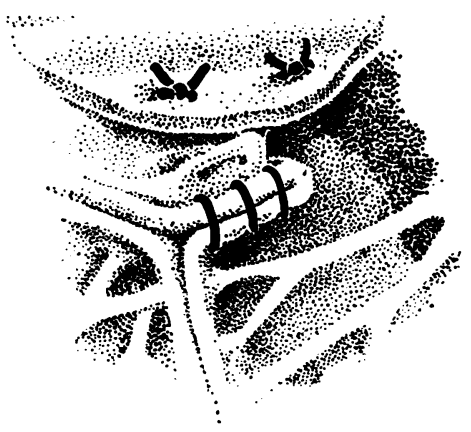

FIG. 6. To avoid a tricuspid insufficiency the septal tricuspid leaflet remaining in the right ventricle was sutured to. the edge of the anterior tricuspid leaflet. 
not due to the repaired incision in the tricuspid leaflet but to rupture of a chorda tendinea due to trauma during surgery. A significant tricuspid insufficiency was palpated after decannulation. A second period of bypass was instituted, and the edge of the septal tricuspid leaflet with the ruptured chorda was sutured to the edge of the anterior tricuspid leaflet. A small insufficiency was palpated at the end of the operation, and eight months later a mean pressure of $8 \mathrm{~mm}$. $\mathrm{Hg}$ was found in the right atrium with a systolic pressure wave of $12 \mathrm{~mm} . \mathrm{Hg}$ at a right ventricular pressure of $80 \mathrm{~mm}$. $\mathrm{Hg}$.

Regarding the transatrial approach in patients with tetralogy of Fallot it was necessary to make an incision in the tricuspid leaflet in five out of six cases. In one additional patient, a 57-year-old man, the transatrial approach was first tried but gave a bad exposure and had to be abandoned in favour of a ventricular incision. As there was no ridge between the pulmonary artery and the aorta the upper sutures to the patch were inserted through the base of the pulmonary artery.

In patients with tetralogy of Fallot an abnormal distribution of the coronary arteries may increase the risk of a ventriculotomy, and in these circumstances the atrial approach could be used as an alternative. It should first be verified by angiocardiography that no outflow prosthesis is needed. The ventricular septal defect can usually be exposed through the base of the septal tricuspid leaflet as easily as in an isolated ventricular septal defect. A pulmonary valvular stenosis is opened by a transverse incision in the pulmonary artery. The infundibular resection is more difficult and time-consuming through the atrial approach. Although only one of the six patients with Fallot's tetralogy operated through the atrium died, a decrease in the right ventricular pressure to $35 \mathrm{~mm}$. $\mathrm{Hg}$ was only obtained in one patient. In four patients the right ventricular pressure remained at 70 to 80 $\mathrm{mm}$. $\mathrm{Hg}$ and in the last patient it remained at $60 \mathrm{~mm}$. $\mathrm{Hg}$.

In conclusion the right atrial approach is favoured in all cases of isolated ventricular septal defects.

In cases of Fallot's tetralogy the atrial approach can be used with a good result. There is a technical disadvantage during infundibular resection, however, which makes a ventriculotomy preferable for patients with Fallot's tetralogy.

\section{THE TRANS-AORTIC APPROACH}

The trans-aortic approach for closure of a ventricular septal defect has been used in two patients in whom an aortic insufficiency was the dominant lesion.

In a 46-year-old man a ventricular septal defect of $10 \mathrm{~mm}$. diameter was closed by direct suture-mattress sutures placed through the base of the right sinus of Valsalva. A total aortic valve prosthesis was also inserted. The patient died from sepsis four months later when the ventricular septal defect was found to be completely closed.
The second patient was a 20-year-old woman with a defect of 20 to $15 \mathrm{~mm}$. diameter which was closed with a patch through the right atrium. A concomitant severe aortic insufficiency was treated two years later with a Starr-Edwards ball valve prosthesis when a $5 \times 5 \mathrm{~mm}$. defect caused by suture insufficiency in the upper portion of the patch was found. This defect was closed by a patch of aortic valvular tissue turned down into the left ventricle and sutured to the old dacron patch (Fig. 7). The cuff of the ball valve prosthesis was then used as a reinforcement (Fig. 8). The patient made an uneventful recovery.

\section{COMPLICATED CASES}

VENTRICUlaR SEPTAL DEFECT WITH PATENT DUCTUS ARTERIOSUS In patients under the age of 2 years with a ductus as well as an isolated ventricular septal defect the ductus has been divided at a first operation and the ventricular septal defect closed at a later date.

In older patients a one-stage procedure has been used. The patient is placed on total cardiopulmonary
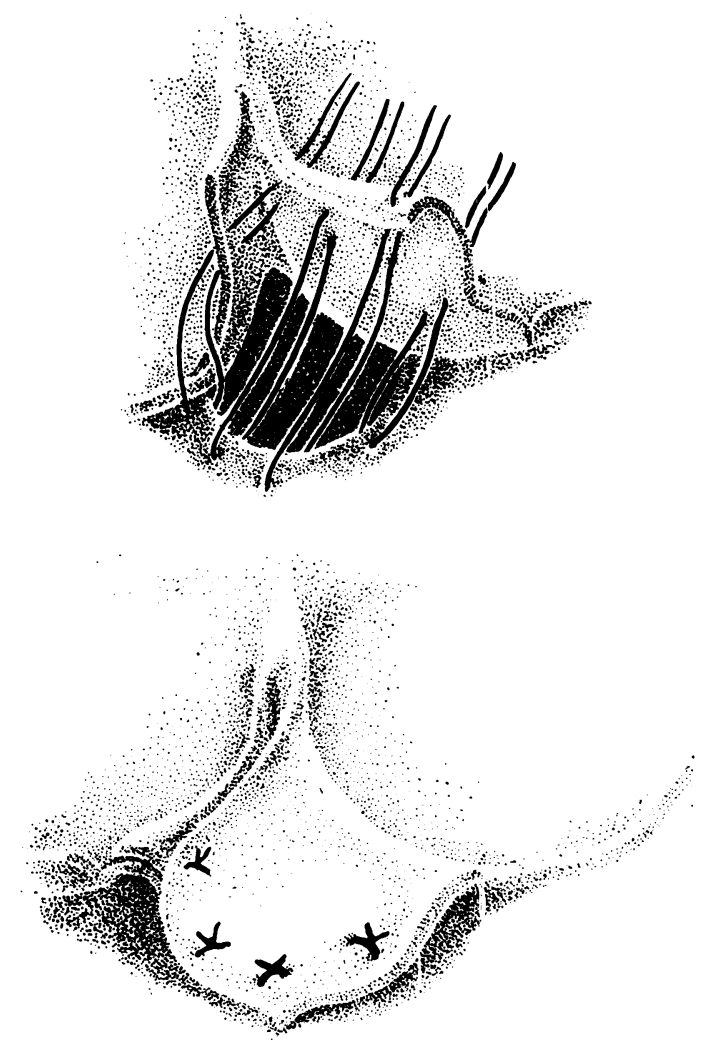

FIG. 7. The remaining part of aortic valvular tissue was used as a patch turned down and sutured to the old dacron patch. 


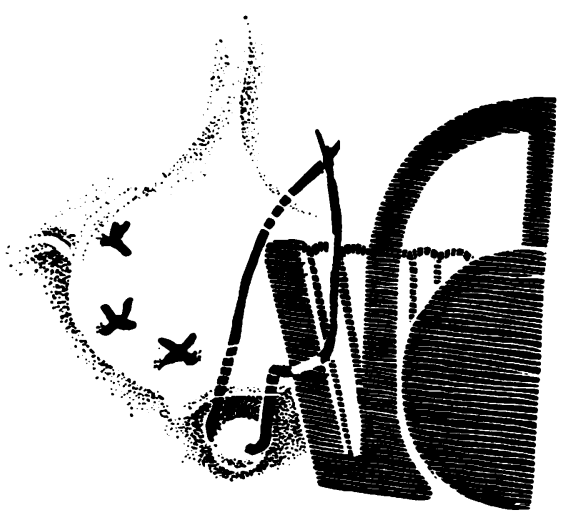

FIG. 8. Fixation of the cuff of the ball valve prosthesis as a second layer over the ventricular septal defect.

bypass and the body temperature is brought down to $30^{-}$to $25^{\circ}$ C. The circulation is then completely arrested for five to 10 minutes, the main pulmonary artery is opened with a longitudinal incision, which may be extended into the left pulmonary artery, and the ductus is closed from the inside of the pulmonary artery with a running suture. If more time is needed the circulation is continued with the heart/lung machine while the ductus is closed with the surgeon's fingertip. When an undiagnosed ductus has been found during open heart surgery the pulmonary artery is opened and the ductus is occluded with a finger while the temperature is brought down so that the circulation can be arrested.

In this series the combined procedures were carried out twice. In a 4-vear-old boy with a huge heart of $980 \mathrm{ml} . / \mathrm{m}^{2}$ body surface the circulation was arrested for $8 \mathrm{~min}$. at $23^{\circ} \mathrm{C}$. for closure of the ductus. Then a $10 \times 10 \mathrm{~mm}$. defect was closed with a patch from the right atrium. The time on bypass was 42 minutes. Recovery was uneventful. After one month the heart had decreased to $720 \mathrm{ml} . / \mathrm{m}^{2}$, after two months to $440 \mathrm{ml} . / \mathrm{m}^{2}$, and after one year to $420 \mathrm{ml} . / \mathrm{m}^{2}$. The pulmonary artery pressure was $50 \mathrm{~mm}$. $\mathrm{Hg}$ before and $30 \mathrm{~mm}$. $\mathrm{Hg}$ after one year when no shunt was found at catheterization.

The second patient was a 38-year-old woman in whom a ductus was found after opening the heart. The circulation was arrested for 2 min. when the pulmonary artery was opened and the ductus was occluded by a finger. During $6 \mathrm{~min}$. of perfusion the temperature was brought down to $29^{\circ} \mathrm{C}$. and the circulation was again arrested for $5 \mathrm{~min}$., when five isolated mattress sutures from the inside of the pulmonary artery closed the ductus. Then a 20 to $15 \mathrm{~mm}$. diameter ventricular septal defect was closed with a patch through the right atrium after an incision in the septal tricuspid leaflet. The patient recovered and the heart size decreased from $840 \mathrm{ml} . / \mathrm{m}^{2}$ to $550 \mathrm{ml} . / \mathrm{m}^{2}$. The right ventricular pressure before operation was $100 \mathrm{mg}$. $\mathrm{Hg}$, at the end of operation $55 \mathrm{mg}$. $\mathrm{Hg}$, and one and a half years later only $33 \mathrm{~mm}$.
$\mathrm{Hg}$ when no shunt could be demonstrated at catheterization.

VENTRICULAR SEPTAL DEFECT WITH PULMONARY VALVULAR STENOSIS Cases combined with pulmonary valvular stenosis and a left-to-right shunt are approached with two incisions, transatrial for the ventricular septal defect and a transverse incision in the pulmonary artery. In pulmonary valvular stenosis it is nearly always necessary to begin by freeing the fused commissures from the arterial wall before two incisions are made in the commissures. This technique was used in a 21-year-old man with a left-to-right shunt of 4.7 litres $/ \mathrm{min}$. and a right ventricular pressure of $100 \mathrm{~mm}$. $\mathrm{Hg}$. The pressure immediately decreased to $30 \mathrm{~mm}$. $\mathrm{Hg}$ and no shunt was detected two years after operation.

VENTRICULAR SEPTAL DEFECT AND AORTIC INSUFFICIENCY Smaller defects are approached through the aortic incision at the same time as a total valve prosthesis is inserted. This was done in two patients.

If the shunt and defect are big, a two-stage procedure with closure of the ventricular septal defect through the right atrium is performed at the first operation. The valve prosthesis is then introduced at a second stage. This was successfully done in a 20year-old woman with a defect of 20 to $15 \mathrm{~mm}$. diameter. The aortic insufficiency was not improved after the first stage, and a ball valve prosthesis was inserted two years later.

An attempt to correct the aortic insufficiency through a 25 to $15 \mathrm{~mm}$. diameter ventricular septal defect by bicuspidalization in a 15-year-old girl was not successful. The insertion of a ball valve prostheșis in the aortic orifice through a large ventricular septal defect is theoretically possible, but coronary perfusion would be impossible without aortotomy.

A ventricular septal defect was combined with infundibular stenosis and pulmonary valvular stenosis as well as a severe aortic insufficiency and a huge heart of more than $700 \mathrm{ml} . / \mathrm{m}^{2}$ body surface in one 15-year-old and one 19-year-old patient. An aortic valvular prosthesis was inserted as well as a patch in the ventricular septal defect and a right infundibular resection and pulmonary valvular commissurotomy during slightly more than 2 hours' perfusion; in both patients there was a good local result. One patient died of a brain embolism from a thrombosis at the base of a tefion aortic prosthesis; the other, in whom a ball valve aortic prosthesis had been used, died from circulatory failure. It seems that a complete correction of such a complicated lesion in one stage is too extensive an operation. Further experience with one successful case of closure of a ventricular septal defect in one stage and the introduction of a ball valve prosthesis at a later date in a 20-year-old woman speaks in favour of a two-stage procedure.

VENTRICULAR SEPTAL DEFECT COMBINED WITH A RUPTURED SINUS OF VALSALVA ANEURYSM In a 32year-old man with a huge heart of $800 \mathrm{ml} . / \mathrm{m}^{2}$, a 
ruptured sinus of Valsalva aneurysm was diagnosed and verified at cardiotomy through the right ventricle. A high $7 \mathrm{~mm}$. diameter ventricular septal defect was also found and closed by direct suture. Catheterization one year later showed no shunt, the pulmonary artery pressure had decreased from $40 \mathrm{~mm} . \mathrm{Hg}$ to $23 \mathrm{~mm}$. $\mathrm{Hg}$, and the working capacity had increased from 400 to 800 kilopondmeters/minute.

TRAUMATIC VENTRICUlar SEPTAL DEFECT A 15-yearold boy had been treated for a pulmonary valvular stenosis by a transventricular dilatation in 1954. At operation severe bleeding was noted when the dilator emerged outside the heart at the left of the root of the pulmonary artery. A traumatic ventricular septal defect had been caused as well as a lesion of the left descending coronary artery which was ligated. Later on a large anterior infarction developed and the pulmonary valvular stenosis remained. Direct suture of the ventricular septal defect and commissurotomy of the pulmonary valve through the artery was performed. There was failure of the circulation which had to be supported by massage before the patient was connected to the heart/lung machine, and the patient did not survive the operation.

In a 16-year-old girl with an isolated infundibular stricture a right transventricular dilatation in 1955 caused a traumatic ventricular septal defect (Fig. 9). The right ventricular pressure remained at $136 \mathrm{~mm}$. $\mathrm{Hg}$. At operation the infundibular stricture was resected and a $15 \mathrm{~mm}$. diameter traumatic ventricular

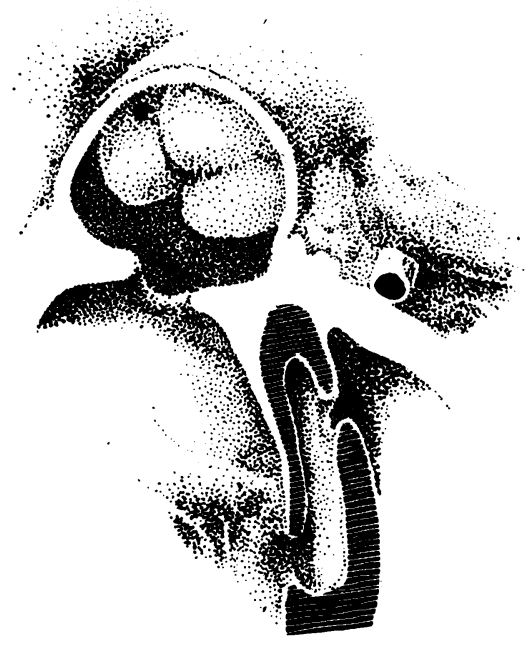

FIG. 9. Traumatic ventricular septa' defect in a patient with isolated infundibular stricture. septal defect with fibrotic edges was closed by direct sutures over teflon strips. Later a second small defect in the membranous septum of the usual type was also found and closed by direct suture. The right ventricular pressure decreased from $136 \mathrm{~mm}$. $\mathrm{Hg}$ to $25 \mathrm{~mm}$. $\mathrm{Hg}$ at the end of operation. The patient made an uneventful recovery.

RECURRENT VENTRICULAR SEPTAL DEFECT Four cases of recurrent ventricular septal defect after direct suture were easily closed by direct sutures through a thickened and fibrotic rim. The recurrent defect was always found posteriorly at the edge of the septal tricuspid leaflet. Recovery was uneventful in all four patients. Excessive post-operative bleeding was avoided by delayed closure. In all re-operations the closure of the wound was delayed for one to two hours until all oozing had ceased.

\section{SUMMARY}

The surgical technique of closure of ventricular septal defects in 80 cases (37 cases of isolated defects and 43 cases of tetralogy of Fallot) is discussed in the light of the follow-up results. The use of a patch for closure has reduced the incidence of recurrence to $4 \%$, compared with $18 \%$ when direct suture was performed. The incidence of heart block also decreased from $15 \%$, when direct suture was used, to $4 \%$ with a patch. The transatrial approach is preferred for isolated ventricular septal defects; the ventricular approach is preferred for cases with tetralogy of Fallot. In cases combined with aortic insufficiency only small defects are closed through the aorta. Larger defects are closed in the usual way at a first stage operation, and a total valve prosthesis is introduced at a second operation. There was an operative mortality of $6 \%$ in isolated ventricular septal defects, compared with $27 \%$ in cyanotic patients with tetralogy of Fallot.

\section{REFERENCES}

Björk, V. O. (1964). The transatrial approach to ventricular septa defect. J. thorac. cardiovasc. Surg., 47, 178.

Cleland, W. P., and others (1958). The treatment of ventricular septal defect. Brit.med. J., 2, 1369.

Cooley, D. A. (1959). Current status of the surgical treatment of ventricular septal defect. Dis. Chest, 35,651 .

Kay, J., and others (1960). The surgical repair of high pressure ventricular septal defect through the right atrium. Surgery, 48, 65 .

Kirklin, J. W., Harshbarger, H. G., Donald, D. E., and Edwards, J. E. (1957). Surgical correction of ventricular septal defect : Anatomic and technical considerations. J. thorac. Surg., 33, 45.

Lillehei, C. W., Cohen, M., Warden, H. E., Ziegler, N. R., and Varco, R. L. (1955). Results of direct vision closure of ventricular septal defects in eight patients by means of controlled cross circulation. Surg. Gynec. Obstet., 101, 446. 